\title{
Abnormal lipid metabolism is associated with angiogenic and anti angiogenic factor imbalance in PIH women
}

\author{
Visala Sree Jammalamadaga $^{1}$, Philips Abraham ${ }^{2 *}$
}

\begin{abstract}
${ }^{1}$ Department of Biochemistry, Annapoorana Medical College and Hospital, Salem, Tamil Nadu, India ${ }^{2}$ Department of Biochemistry, Al-Azhar Medical College and Super Speciality Hospital, Kumaramangalam, Kerala, India
\end{abstract}

Received: 28 June 2017

Accepted: 25 July 2017

\author{
*Correspondence: \\ Dr. Philips Abraham, \\ E-mail: philips4848@yahoo.com
}

Copyright: (c) the author(s), publisher and licensee Medip Academy. This is an open-access article distributed under the terms of the Creative Commons Attribution Non-Commercial License, which permits unrestricted non-commercial use, distribution, and reproduction in any medium, provided the original work is properly cited.

\begin{abstract}
Background: Preeclampsia is a major cause of maternal and fetal/neonatal mortality and morbidity even in developed countries. Despite of extensive research, the etiology and pathogenesis of preeclampsia are not completely understood. Evidence shows that imbalance between angiogenic and antiangiogenic factor plays a pivotal role in the genesis of endothelial dysfunction which is considered as a hall mark in the development of multisystem disorder in pre-eclampsia and eclampsia. Abnormal lipid metabolism is a known causative factor for endothelial dysfunction. This study has been designed to determine the association between abnormal lipids and angiogenic, anti angiogenic balance in PIH (PE and E) women.

Methods: Study group consisted of Normotensive pregnant women (N) preeclamptic women (PE) and eclamptic women (E) with 100 subjects in each group in the 3rd trimester of pregnancy. They were investigated for lipid profile and apolipoproteins, MDA, FRAP, TNF- $\alpha$, sFlt-1, VEGF, PlGF, NO. Statistical analysis was done using ANOVA and pearson correlation analysis.

Results: When compared to controls TC, TGL, VLDL, LDL, apoB, MDA, TNF- $\alpha$, sFlt-1 levels were found to be significantly high and HDL, apoA, FRAP, VEGF, PIGF, and NO levels were significantly low in PE, E group. Eclamptic women showed a significantly high level of MDA, TNF- $\alpha$, sFlt-1and low levels of FRAP, VEGF, PIGF, NO when compared to PE group.

Conclusions: In PIH women, abnormal lipid metabolism is associated with angiogenic and antiangiogenic imbalance.
\end{abstract}

Keywords: Angiogenic and anti-angiogenic factors, Eclamptic women, Lipids, Preeclamptic women

\section{INTRODUCTION}

Hypertensive disorders are the common medical disorders in pregnancy. It has effects both on expectant mother and fetus. The impact of pregnancy induced hypertension $(\mathrm{PIH})$ is very high in India and other developing countries.

The incidence of PIH in India is about $7-10 \%$ of all antenatal admission. PIH is the appearance of hypertension of more than $140 / 90 \mathrm{~mm}$ of $\mathrm{Hg}$ after 20 weeks of gestation. When hypertension is associated with significant proteinuria it is called preeclampsia (PE). PE complicated by seizures is called eclampsia which is a major cause of maternal mortality. ${ }^{1}$

Endothelial dysfunction (ED) plays a focal role in the origin of the multisystem disorder that develops in PE. The mechanisms involved in the induction of ED are poorly understood. Pregnancy is associated with physiological changes such as increase in lipids from first to third trimester in order to satisfy energy and membrane 
demands of the developing fetus. But, in pregnancy related disorders such as PE, maternal plasma lipid levels were abnormally exaggerated. ${ }^{2}$ The disorders in lipoprotein metabolism are one of the most important causes for ED.

Lipid alterations may promote oxidative stress in PE. Reactive oxygen species (ROS) play an important role in placental cellular growth, differentiation, apoptosis and in events which are of critical importance in determining the outcome of pregnancy. Exposure of placenta to a nonphysiological concentration of ROS that induce oxidative stress results in oxidative damage of cellular lipids, proteins, DNA, RNA and also makes placenta relatively hypoxic due to an inadequate uteroplacental circulation which is thought to release placenta derived factors into the systemic maternal circulation leading to maternal endothelial damage, elevated oxidative stress, and systemic inflammation. ${ }^{3}$

So, A study has been designed to evaluate the levels of lipids, apolipoproteins, marker of oxidative stress (MDA) and Total antioxidant capacity (FRAP), inflammatory marker (TNF-alpha), anti-angiogenic factor (sFlt-1) and angiogenic factors (VEGF, PIGF), marker for ED (NO) in $\mathrm{PIH}$ women compare to normotensive pregnant women and to analyze correlation status between lipids and angiogenic, anti-angiogenic factors, NO.

This study might contribute awareness concerning with the involvement of lipids in development of hypertension during pregnancy and also whether lipids can be used as a marker for assessing the onset, progression and severity of the disease rather than avoiding any other costly investigations.

\section{METHODS}

A cross sectional analytical study was conducted in the inpatient ward of the Department of Obstetrics and Gynecology, Annapoorana institute of medical sciences, Salem, Tamilnadu from August 2012 to April 2016. The study was approved by the Institutional Ethics Committee of AMCandH and informed consent was obtained from all participants. PIH patients were defined according to the NHBPEP (National high blood pressure education programme) guidelines 4 .

\section{Patients and controls}

Hundred each normotensive pregnant woman who served as control (Group 1), PE (Group 2) and E (Group 3) patients were selected. The mean SBP in 3 groups were recorded as $(116 \pm 5.45$ vs. $162.18 \pm 18.26$ vs. $170 \pm 15.52)$ $\mathrm{mm} \mathrm{Hg}$. The mean DBP in 3 groups were recorded as $(75 \pm 5.99$ vs. $107.5 \pm 11.35$ vs. $112.28 \pm 10.59) \mathrm{mm} \mathrm{Hg}$. The urine albumin levels in 3 groups were measured as $(150.92 \pm 33.4$ vs. $436 \pm 96$ vs. $432 \pm 101) \mathrm{mg} / \mathrm{d}$. Preeclampsia was defined as having a systolic blood pressure $140 \mathrm{~mm} \mathrm{Hg}$ or a diastolic blood pressure $90 \mathrm{~mm}$
$\mathrm{Hg}$ with proteinuria $300 \mathrm{mg} / \mathrm{d}$. Sign and symptoms of PIH like swelling in the hands, face and feet, severe headaches, abdominal pain, reduced output of urine or no urine, blood in the urine, a change in reflexes, convulsion/seizures, coma, dizziness, excessive vomiting, nausea and rapid gain in weight were recorded. Eclamptic complications like cerebro vascular, cardio vascular, visual, pulmonary, renal, hepatic, haemostatic and obstetrical were also recorded.

\section{Exclusion criteria}

Individuals with past history of cardiac, renal, hepatic illness, diabetes, and hypertensions were excluded.

$8 \mathrm{ml}$ of ante cubital venous blood samples were collected from both patients and controls. The samples were centrifuged at 3000rpm for 20 minutes. Plasma and serum were separated. Aliquots were prepared and stored at $-20^{\circ} \mathrm{C}$ till subsequent use. TC, TGL, HDL, ApoA-I, and ApoB using commercially available standard kits (Agappe diagnostics) in a semi auto analyser. VLDL and LDL values were computed with the friedewald formula. Nitric oxide (NO) was done using Griess method. MDA was done using TBARS.

TAC was estimated using FRAP method. TNF-alpha, IL6 levels were measured using Quantikine ${ }^{\circledR}$ human TNFalpha RandD Systems Inc., Minneapolis, MN, USA. HsCRP levels were measured using ERBA immune turbidometric assay kit. sFlt-1, VEGF and PIGF were measured by a sandwich-type ELISA (Quantikine® human sVEGFR 1, Quantikine ${ }^{\circledR}$ human VEGF, Quantikine ${ }^{\circledR}$ human PIGF, RandD Systems Inc., Minneapolis, MN, USA). The minimum detectable level of the assay is $13.3 \mathrm{pg} / \mathrm{ml}$ for sFlt-1, $9 \mathrm{pg} / \mathrm{ml}$ for VEGF and $7 \mathrm{pg} / \mathrm{ml}$ for PIGF. The intra-assay and inter-assay variations were $3.8 \%$ and $7 \%$ for sFlt $-1,4.5 \%$ and $7 \%$ for VEGF and $3.6 \%$ and $11 \%$ for PlGF, respectively.

\section{RESULTS}

The socio demographic characters between Controls, PE and $\mathrm{E}$ groups were compared in Table 1.

The Maternal age, Gestational weeks, $\mathrm{Hb}$ were almost comparable between the 3 groups. The mean SBP/DBP, BMI was significantly high between the 3 groups. The urine albumin is significantly high in PE, E groups compared to controls.

Table 2, 3, 4 shows the levels of TC, TGL, VLDL, LDL, ApoB-100, MDA, TNF- $\alpha$, sFlt-1 were significantly high in PE, E groups compared to controls and the same levels were significantly high in eclamptic women than in PE women. The HsCRP, IL-6 levels were significantly high in PE, E women than controls. The HDL, ApoA, FRAP, VEGF, PIGF, NO levels were significantly low in PE, E than controls and the same levels were low in eclamptic women than PE. Table 5 shows correlation analysis. 
Table 1: Socio demographic characters among all the groups.

\begin{tabular}{|lllllll|}
\hline Characters & Controls & \multicolumn{4}{c}{ Preeclampsia } & Eclampsia \\
\hline AGE & Mean & SD & Mean & SD & Mean & SD \\
\hline BMI & 23.97 & 3.30 & 24.62 & 4.07 & 25.71 & $3.71^{*}$ \\
\hline Gestation age & 24.37 & 1.80 & 28.1 & 6.08 & 30.2 & $5^{*} \mathrm{a}^{*}$ \\
\hline SBP & 31.57 & 2.67 & 32.42 & 3.12 & 31.05 & 2.90 \\
\hline DBP & 116 & 5.45 & 162.18 & $18.26^{*}$ & 170 & $15.52^{*} \mathrm{a}^{*}$ \\
\hline Urine albumin & 75 & 5.99 & 107.5 & $11.35^{*}$ & 112.28 & $10.59^{*} \mathrm{a}^{*}$ \\
\hline Hb $(\%)$ & 150.92 & 33.4 & 436 & $96 *$ & 432 & $101^{*}$ \\
\hline
\end{tabular}

Table 2: The serum lipid and lipoprotein levels among all the groups.

\begin{tabular}{|ll|ll|}
\hline Parameters & Controls & Preeclampsia & Eclampsia \\
\hline Total cholesterol $(\mathrm{mg} / \mathrm{dl})$ & $209.7 \pm 34.90$ & $223.59 \pm 39.46^{*}$ & $244.14 \pm 43.56 * \mathrm{a}^{*}$ \\
\hline Triglycerides $(\mathrm{mg} / \mathrm{dl})$ & $203.6 \pm 37.31$ & $246.53 \pm 34.29 *$ & $318.48 \pm 78.39 * \mathrm{a}^{*}$ \\
\hline HDL $(\mathrm{mg} / \mathrm{dl})$ & $44.02 \pm 7.71$ & $35.65 \pm 7.64 *$ & $29.97 \pm 4.61 * \mathrm{a}^{*}$ \\
\hline VLDL calculated $(\mathrm{mg} / \mathrm{dl})$ & $40.72 \pm 7.46$ & $49.30 \pm 6.85 *$ & $63.69 \pm 15.67 * \mathrm{a}^{*}$ \\
\hline LDL calculated $(\mathrm{mg} / \mathrm{dl})$ & $124.95 \pm 34.30$ & $138.63 \pm 34.66^{*}$ & $150.47 \pm 46.0 * \mathrm{a}^{*}$ \\
\hline Apo A-1 $(\mathrm{mg} / \mathrm{dl})$ & $184.9 \pm 17.04$ & $131.18 \pm 23.72 *$ & $144.65 \pm 32.05 * \mathrm{a}^{*}$ \\
\hline Apo B-100 $(\mathrm{mg} / \mathrm{dl})$ & $129.22 \pm 16.69$ & $153.82 \pm 26.7 *$ & $182.14 \pm 16.17 * \mathrm{a}^{*}$ \\
\hline
\end{tabular}

Table 3: The antioxidant capacity (AOC), oxidative stress marker among all the groups.

\begin{tabular}{|llll|}
\hline Parameters & Controls & Preeclampsia & Eclampsia \\
\hline MDA $(\mu \mathrm{mol} / \mathrm{L})$ & $1.08 \pm 0.86$ & $4.49 \pm 1.75^{*}$ & $5.50 \pm 1.97 * \mathrm{a}^{*}$ \\
\hline FRAP $(\mu \mathrm{mol} / \mathrm{L})$ & $2.21 \pm 0.89$ & $0.67 \pm 0.42^{*}$ & $0.407 \pm 0.38 * \mathrm{a}^{*}$ \\
\hline
\end{tabular}

Of the 6 babies who required immediate resusucitation, one expired in immediate neonatal period due to birth asphyxia (intrapartum fetal distress at 32 weeks in woman with severe preeclampsia), one expired after 10 days due to metabolic complications and the rest four survived.

Table 4: The levels of inflammatory markers, angiogenic and anti angiogenic factors among all the groups.

\begin{tabular}{|llll|}
\hline Parameters & Controls & Preeclampsia & Eclampsia \\
\hline TNF- $\alpha(\mathrm{pg} / \mathrm{ml})$ & $10.51 \pm 3.00$ & $22.17 \pm 8.04^{*}$ & $27.50 \pm 14.07^{*} \mathrm{a}^{*}$ \\
\hline IL-6 $(\mathrm{pg} / \mathrm{ml})$ & $2.64 \pm 0.73$ & $9.57 \pm 3.26^{*}$ & $10.13 \pm 3.25^{*}$ \\
\hline HsCRP $(\mathrm{mg} / \mathrm{L})$ & $2.05 \pm 0.58$ & $7.51 \pm 1.67^{*}$ & $7.59 \pm 2.89^{*}$ \\
\hline sFlt-1 $(\mathrm{pg} / \mathrm{ml})$ & $1271.22 \pm 365.22$ & $3854.12 \pm 741.97^{*}$ & $7827.57 \pm 1841.29^{*} \mathrm{a}^{*}$ \\
\hline VEGF $(\mathrm{pg} / \mathrm{ml})$ & $274.05 \pm 36.15$ & $179.12 \pm 18.87^{*}$ & $131.48 \pm 36.93^{*} \mathrm{a}^{*}$ \\
\hline PlGF $(\mathrm{pg} / \mathrm{ml})$ & $682.97 \pm 212.19$ & $225.56 \pm 56.46^{*}$ & $141.63 \pm 121.74^{*} \mathrm{a}^{*}$ \\
\hline
\end{tabular}

Table 5: The levels of nitric oxide among all the groups.

\begin{tabular}{|llll} 
Parameter & Controls & Preclampsia & Eclampsia \\
\hline $\mathrm{NO}(\mu \mathrm{mol} / \mathrm{L})$ & $117.37 \pm 14.77$ & $38.6 \pm 9.94 *$ & $38.6 \pm 9.94 * a *$
\end{tabular}

\section{DISCUSSION}

Pregnancy induced hypertension is the most common medical problem during pregnancy and is associated with increased risk of adverse fetal, neonatal and maternal outcomes, including preterm birth, intrauterine growth restriction (IUGR), perinatal death, acute renal or hepatic failure, antepartum hemorrhage, postpartum hemorrhage and maternal death. ${ }^{5}$ Though it is postulated that the initiating event in PIH is reduced placental perfusion due to abnormal placentation, elevated plasma lipids are believed to be probable cause of endothelial cell activation. $^{6,7}$ In this regard, our study displayed a significant high level of TC, TGL, VLDL, LDL, ApoB and a significant low level of HDL, ApoA-1 between 
controls than PE, E women and also between PE and E women.

Table 6: Correlation of lipids and lipoproteins with angiogenic and anti-angiogenic factors and NO.

\begin{tabular}{|lllll|}
\hline Parameter & VEGF & PIGF & sFlt-1 & NO \\
& r value & r value & r value & r value \\
\hline TC & $-0.357^{* *}$ & $-0.332^{* *}$ & $0.425^{* *}$ & $-0.319^{* *}$ \\
\hline TGL & $-0.633^{* *}$ & $-0.559^{* *}$ & $0.624 * *$ & $-0.545^{* *}$ \\
\hline HDL & $0.540^{* *}$ & $0.538^{* *}$ & $-0.583 * *$ & $0.563 * *$ \\
\hline LDL & $-0.264 * *$ & $-0.264 * *$ & $0.347 * *$ & $-0.261 * *$ \\
\hline VLDL & $-0.633^{* *}$ & $-0.559 * *$ & $0.624 * *$ & $-0.545^{* *}$ \\
\hline ApoA & $0.410^{* *}$ & $0.515^{* *}$ & $-0.328^{* *}$ & $0.493^{* *}$ \\
\hline ApoB & $-0.633^{* *}$ & $-0.562 * *$ & $0.626^{* *}$ & $-0.614^{*}$ \\
\hline
\end{tabular}

Pregnancy is associated with insulin resistance. ${ }^{8}$ The observed hypertriglyceridemia might be due to the insulin resistant visceral fat which results in increased flux of fatty acids to the liver via portal vein which leads to hepatic steatosis due to an increase in TGL synthesis and increase in the blood VLDL. ${ }^{9}$ It could also be due to low activity of LPL, an insulin-dependent endothelial enzyme. Because of the decrease in the activity of LPL, the removal of chylomicrons and VLDL from circulation is low in Insulin resistant patients. Thus, VLDL remains in the plasma for a longer time leading to the accumulation of LDL. ${ }^{10}$ APO-B is a protein component of a variety of lipoproteins such as Chylomicrons, LDLC, VLDL-C, IDL-C and lipoprotein (a). In most conditions, more than $90 \%$ of all ApoB in blood is found in LDL. ${ }^{11}$

Hypertriglyceridemia play a part in decreasing the HDLcholesterol. Impaired transport of cholesterol from peripheral tissues to the target area of utilization may cause the decrease in HDL-cholesterol in serum. There is a direct correlation between adipose tissue lipoprotein lipase activity and plasma HDL cholesterol which might be responsible for low levels of HDL cholesterol. ${ }^{12}$ The increased TGL is likely to be deposited in predisposed vessels, such as the uterine spiral arteries and contributes to the activation of endothelial cells leading to the production of placental derived factors which can be considered as probable contributors for the pathogenesis of PIH. ${ }^{10,13}$

Present study showed a significant high MDA level and significant low levels of FRAP in PE and E women compared to the controls and the same was displayed between $\mathrm{PE}$ and $\mathrm{E}$ women. This might be due to hyperlipidemia which may contribute to the promotion of oxidative stress which is believed to result from increased formation of lipid peroxides, ROS and superoxide anion radicals, leading to an imbalance in production between prooxidant and antioxidant defences. ${ }^{14,15}$ The degree of deficiency in implantation and conversion of the spiral arteries has also been proposed to influence the degree of oxidative stress which disturbs the normal redox state of the cell. The more severe oxidative stress can also result in cell death. Oxidative stress and tissue damage cause a rupture in the barrier and create a leakage of fetal and placenta-derived factors or material into the maternal circulation leading to maternal endothelial damage, elevated oxidative stress, and systemic inflammation. ${ }^{3}$ In this regard our study displayed significant high levels of inflammatory marker TNF- $\alpha$ in PE, E women than controls. The levels of TNF- $\alpha$ were significantly high in eclamptic women than in PE women. This might be due to hypoxia-induced up regulation of placental inflammatory cytokines. Intermittent perfusion of the placenta, secondary to reduced trophoblast invasion, causes increased secretion of TNF- $\alpha{ }^{16}$

Present study displayed significant high levels of sFlt-1 in $\mathrm{PE}, \mathrm{E}$ than controls and the levels were significantly high in eclamptic women than in PE. A study by Sydney et al had stated that TNF-alpha may stimulate sFlt-1 production through an indirect mechanism, possibly mediated by the Angiotensin type II receptor agonistic autoantibodies (AT1-AA). Alternatively, under chronic conditions TNF-alpha can directly stimulate the sFlt-1 production. The placental hypoxia that exists in PE women could also be responsible for up regulation of sFlt1 expression. ${ }^{17}$

Flt-1 receptor, which binds to VEGF and its homologue PlGF, exists in two forms: 1) a membrane-bound receptor tyrosine kinase (Flt1) which transmits angiogenic signals. 2) A soluble secreted ectodomain (sFlt1) which only captures VEGF and PlGF. ${ }^{18}$ As sFlt1 lacks a cytosolic domain, its function is restricted to regulating (reducing) the levels of free VEGF and PlGF available to signal via intact Flt1 and flk-1. Thus, it blunts the beneficial effects of these factors on maternal endothelium. ${ }^{19}$ In this concern, our study displayed a significant low level of VEGF, PIGF in PE, E women than controls. However, studies on circulating levels of VEGF in preeclampsia have been inconsistent, with reports of both increased and decreased levels. This discrepancy could be explained by the fact that VEGF-protein complexes are undetectable by the sandwich-type ELISA because there is a substantial increase in circulating VEGF binding proteins during pregnancy.

All prior studies reporting on decreased VEGF have used an ELISA kit, which measures free (unbound) VEGF whereas all studies reporting on an increased VEGF in preeclampsia used either a radioimmunoassay or an ELISA system measuring total (bound and unbound) VEGF. ${ }^{20}$ In this study we estimated free VEGF and PIGF levels. The reduced VEGF levels might be a reason for observed hypertension and proteinuria among $\mathrm{PE}$ and $\mathrm{E}$ women because VEGF is important in regulation of blood pressure and maintaining the integrity of glomerular filtration barrier. It also has a role in glomerular healing. Alterations in the VEGF bioavailability might have resulted in endothelial as well as podocyte damage. ${ }^{21}$ In present study, the VEGF and PIGF levels were significantly low in eclamptic women compared to the PE 
women. This might be the reason for the disruption of endothelial cells by disrupting the endothelial cells that maintains blood-brain barrier and/or endothelial cells lining the choroid plexus of the brain thus leading to cerebral edema and seizures seen in eclampsia. ${ }^{22}$

Present study displayed significantly low levels of NO, which is a marker for $\mathrm{ED}$ in $\mathrm{PE}$ and $\mathrm{E}$ women than in controls. The levels of NO were significantly low in eclamptic women than in preeclamptic women. This observed low level of NO can be explained as a consequence of reduced level of free VEGF as it plays a major role in the expression of eNOS and in the release of NO. ${ }^{23}$ Another reason might be due to the increased serum levels of LDL in PE and $\mathrm{E}$ women which undergoes oxidation resulting in the generation of oxidized LDL. Ox-LDL can bind to the lectin-like oxidized LDL receptor-1 (LOX-1) on endothelial cells which is responsible for the binding, uptake, and degradation of oxLDL. The binding of oxLDL activates the NADPH oxidase enzyme system, resulting in the excessive generation of superoxide which scavenges the NO and reduces its bioavailability leading to defective endothelial function. ${ }^{24}$

Present correlation analysis reveals that as the levels of lipid and lipoprotein increases, the angiogenic and anti angiogenic imbalance, ED also increases.

\section{CONCLUSION}

The levels of lipids and lipoproteins increases with the severity of the disease. A simple routine monitoring of lipids and lipoproteins may have a predictive role in the assessment of onset, progression and severity of the disease. It is inexpensive and cost effective than other investigations which can be measured in all clinical laboratories.

Funding: No funding sources Conflict of interest: None declared

Ethical approval: The study was approved by the Institutional Ethics Committee

\section{REFERENCES}

1. Kintiraki E, Papakatsika S, Kotronis G, Goulis DG, Kotsis V. Pregnancy-induced hypertension: review. Hormones. 2015;14(2):211-23.

2. Hubel CA. Oxidative stress in the pathogenesis of preeclampsia. Proc Soc Exp Biol Med. 1999;222(3):222-35

3. Hansson SR, Nääv Å, Erlandsson L. Oxidative stress in preeclampsia and the role of free fetal hemoglobin. Frontiers in physiology. 2014;5.

4. Program NH. Report of the national high blood pressure education program working group on high blood pressure in pregnancy, national high blood pressure education program working group on high blood pressure in pregnancy. Am J Obstet Gynecol. 2000;183(1):S1-S22.

5. Sajith M, Nimbargi V, Modi A, Sumariya R, Pawar A. Incidence of pregnancy induced hypertension and prescription pattern of antihypertensive drugs in pregnancy. Int J Pharma Sci Res. 2014;23:4.

6. Granger JP. Role of endothelial dysfunction in pregnancy-induced hypertension. Am J Hypertens. 2000;13(S2):324A

7. Lorentzen B. Plasma lipids and vascular dysfunction in preeclampsia. Semin Reprod Endocrinol. 1998;16(1):339.

8. Catalano PM. Obesity, insulin resistance, and pregnancy outcome. Reproduction. 2010;140(3):36571.

9. Soca PEM. Dyslipidemia in preeclampsia syndrome. Cor Salud. 2013;5(2):221-5.

10. Phalak P, Tilak M. Study of lipid profile in preeclampsia. Indian J Basic Appl Med Res. 2012;5(2):405-9.

11. Maartje E. Apolipoprotein B synthesis inhibition: results from clinical trials. Curr Opinion Lipidol. 2010;21:319-323.

12. Ekhator CN, Ebomoyi MI. Blood glucose and serum lipid profiles during pregnancy. Afr $\mathrm{J}$ Diab Med. 2012;20(1).

13. Kaloti AS, Kaur C, Goel RK, Jha S. Lipid profile trends in women of pregnancy induced hypertension cases in a rural setup. JEMDS. 2013;2(13):2024:31.

14. Owiredu WK. Lipid profile and lipid peroxidation among Ghanaian pregnancy-induced hypertensives. J Med Sci. 2008;8(8):691-8.

15. Adeniji AO, Oparinde DP. Comparison of lipid peroxidation and anti-oxidant ac-tivities in preeclamptic and normal pregnancies in Nigerian Population. Int J Clin Med. 2013;4(05):239.

16. Hung TH, Charnock-Jones DS, Skepper JN, Burton GJ. Secretion of tumor necrosis factor- $\alpha$ from human placental tissues induced by hypoxia-reoxygenation causes endothelial cell activation in vitro: a potential mediator of the inflammatory response in preeclampsia. Am J Pathol. 2004;164(3):1049-61.

17. Murphy SR, LaMarca BB, Parrish M, Cockrell K, Granger JP. Control of soluble fms-like tyrosine-1 (sFlt-1) production response to placental ischemia/hypoxia: role of tumor necrosis factor- $\alpha$. Am J Physiol Regul Integr Comp Physiol. 2013;304:R130-5.

18. Luttun A, Carmeliet P. Soluble VEGF receptor Flt1: the elusive preeclampsia factor discovered? J Clin Invest. 2003;111(5):600.

19. Stepan H, Geide A, Faber R. Soluble fms like tyrosine kinase-1. N Engl J Med. 2004;351:2241-2.

20. Lee ES, Oh MJ, Jung JW, Lim JE, Seol HJ, Lee KJ, Kim HJ. The levels of circulating vascular endothelial growth factor and soluble Flt-1 in pregnancies complicated by preeclampsia. J Korean Med Sci. 2007;22(1):94-8. 
21. Müller-Deile J, Schiffer M. Renal involvement in preeclampsia: similarities to VEGF ablation therapy. Journal of pregnancy. 2010;2011.

22. Khvorova A, Moore M, Turanov AA, Karumanchi A. United States Patent, Karumanchi, Beth Israel Deconess Medical Center, May 13, 2013.

23. Shen BQ, Lee DY, Zioncheck TF. Vascular endothelial growth factor governs endothelial nitricoxide synthase expression via a KDR/Flk-1 receptor and a protein kinase $\mathrm{C}$ signaling pathway. J Biologic Chem. 1999;274(46):33057-63.
24. Sankaralingam S, Xu Y, Sawamura T, Davidge ST. Increased lectin-like oxidized low-density lipoprotein receptor-1 expression in the maternal vasculature of women with preeclampsia. Hypertension. 2009;53(2):270-7.

Cite this article as: Jammalamadaga VS, Abraham P. Abnormal lipid metabolism is associated with angiogenic and anti angiogenic factor imbalance in PIH women. Int J Reprod Contracept Obstet Gynecol 2017;6:3983-8. 